\title{
Effects of Plant Density, Seeding and Harvest Time on the Growth of Two Kenaf (Hibiscus cannabinus L.) Varieties
}

\author{
Lorenzo Barbanti ${ }^{* 1}$, Nicola Di Virgilio ${ }^{2}$, Gianpietro Venturi ${ }^{1}$ \\ ${ }^{1}$ Dipartimento di Scienze e Tecnologie Agroambientali (DiSTA), Università di Bologna \\ Viale G. Fanin 44, 40127 Bologna, Italy \\ ${ }^{2} \mathrm{CNR}$, Istituto di Biometeorologia (IBIMET) \\ Via P. Gobetti 101, 40129 Bologna, Italy
}

Received: 8 June 2008. Accepted: 9 September 2008.

\begin{abstract}
Kenaf is an annual $\mathrm{C}_{3}$ multipurpose crop for the fibre and energy industry, whose growth has been widely investigated in the tropics, but not at relatively-high latitudes. This work aimed at evaluating the effects of two genotypes (Tainung 2 and Everglades 41), two plant densities (20 and 40 plants $\mathrm{m}^{-2}$ ), two seeding times (S1 and S2) and two harvest times (H1 and $\mathrm{H} 2)$ on growth and its relations with climatic factors over three years (2003-2005) in Northern Italy $\left(\right.$ c. $45^{\circ} \mathrm{N}$ ). Fitting curves for whole-plant dry biomass (DB) and dry stems (DS) on heat sums always gave a reliable description of the growth pattern along the season, explaining over $90 \%$ of the total variation. In general, the best-fitting models were the sigmoid and the exponential one for DB and DS, respectively. Among the four studied factors, only seeding time originated consistent growth differences among years, whereas the two varieties showed an equivalent behaviour, as well as the two densities. Furthermore, the thinner density allowed savings in the cost of seed at no prejudice for yield potential. S1 in general showed higher asymptotic yields than S2 in 2003 and 2004, while S2 consistently grew faster than $\mathrm{S} 1$ in all the three years. RUE showed a generally low value (e.g., $1.35 \mathrm{~g} \mathrm{MJ}^{-1}$ for DB in S1), indicating a moisture constraint on crop growth, especially in the first year. As for the correlations, three traits, plant height, base stem diameter and fresh biomass, resulted significantly associated to DB and DS, with correlation coefficients (r) ranging from 0.65 to 0.90 ; a higher degree of association with DB and DS was achieved by the multiple linear regressions of the same three traits (adj. $\mathrm{R}^{2}$ of about 0.85). A high dependence of DB and especially of DS on associated heat and rain (adj. $\mathrm{R}^{2} 0.76$ and 0.86 , respectively) was also observed in the variable environmental conditions among the three years, which attributes a non-negligible power of prediction to the two environmental parameters. These results offer the opportunity of estimating growth through the measure of non-destructive crop variables of easier assessment, and encourages their adoption, in association with that of simple climatic factors (temperatures, precipitation) as tools of potential support to facilitate biomass assessments in commercial fields.
\end{abstract}

Key-words: kenaf, growing pattern, environment, traits correlation, empirical models.

\section{Introduction}

Kenaf (Hibiscus cannabinus L.) is a short-day annual herbaceous $\mathrm{C}_{3}$ plant that belongs to the Malvaceae family. It is a fast-growing crop of tropical origin, whose high leaf photosynthetic rate compares to $\mathrm{C}_{4}$ plants (Shimizu et al., 2004).

Kenaf is mainly grown for the soft bast fibre contained in its stems (Dempsey, 1975), although in the latest years it has been considered as a multi-purpose crop with high productivity and low input requirements (USDA, 1993; Liu, 2003). In the USA, recent research has demonstrated several potential uses for both stem components (bark and core; Taylor, 1992). Kenaf fibre can be an excellent source for several uses such as fabrics, paper, insulation mats, particleboards, substitute of fibreglass and other synthetic fibres, bedding material and litters, oil absorbent, etc. (Kugler, 1990; USDA, 1993). The residual core fraction can be used as biomass for energy production (Danalatos and Archon-

\footnotetext{
* Corresponding Author: Tel.: +39 051 2096643; Fax: +39 051 2096241. E-mail address: lorenzo.barbanti@unibo.it.
} 
toulis, 2005). As an alternative, young plants and ground leaves have a high digestibility and can be used as a source of roughage and protein for cattle and sheep (Hays, 1989; Webber, 1993).

Kenaf has been widely investigated at low latitudes such as in the Southern USA (Fuller, 1994) and in tropical areas (Carberry and Muchow, 1992; Carberry et al., 1992). Interest for the crop has also risen in Europe, although a few data concerning its adaptability, growth patterns and biomass yields are available in temperate areas. Relevant scientific references are reported in a review by Di Virgilio et al. (2004), covering the works carried out during the 1990's in Italy, Spain and Greece: they mainly concern final yield levels and plant morphological growth-related traits, without particular insight into growing patterns and their relations with climatic factors.

In recent years, trials have been resumed under the rising interest for kenaf, in order to study the adaptability of new varieties, with respect to the performances registered under various environmental conditions (soil, weather) and cropping options (seeding and harvest time; plant density).

According to their flowering time, kenaf varieties are divided into early and late maturing ones. Late maturing varieties are generally better yielding compared to the early ones, due to their longer vegetative phases (Petrini et al., 1994; Alexopoulou et al., 2000). Among the latematurity varieties, Tainung 2 and Everglades 41 were found quite promising (Alexopoulou et al., 2000; Angelini et al., 1998), with maximum total dry matter production of 20-24 $\mathrm{t} \mathrm{ha}^{-1}$ (Alexopoulou et al., 2000).

Concerning plant density, a large number of researches has been carried out worldwide in order to enhance crop yields. In most of these studies, the increase of the plant density from 15 to 35 plants $\mathrm{m}^{-2}$ resulted in higher dry matter yields (Higgins and White, 1970; White et al., 1971). Optimum density should be assessed according to the response of the yield components (Muchow, 1979), as well as to the influence of plant branching, as this affects harvest ease. At a relatively low latitude $\left(35^{\circ}\right)$ and with a relatively wide inter-row $(0.76 \mathrm{~m})$, a final plant populations of 18.5 to 37 plants $\mathrm{m}^{-2}$ showed desirable for the production of single stalk plants with very little or no branching (Webber et al., 2002). At lower plant populations the crop produces plants with multiple branches, rather than the desirable single plants which are easier to be machine-harvested. At higher populations (> 37 plants $\mathrm{m}^{-2}$ ) the crop compensates for the available environmental resources (light, soil moisture and nutrients) by reducing the total number of plants to a more desirable population (Webber et al., 2002). Preliminary results at somewhat-higher latitudes and with a narrower inter-row $(0.5 \mathrm{~m})$ indicate that populations of $20-25$ plants $\mathrm{m}^{-2}$ may be adequate for growth, for radiation use efficiency and hence for maximum final biomass yield (Cosentino et al., 2004), although further proofs are clearly needed.

Phenology is another determinant of kenaf yield potential, since maximum stem yield occurs soon after flowering (Wood et al., 1983). Since kenaf is a photoperiod sensitive plant whose flowering is delayed as day length increases, early seeding may enhance stem growth in periods of favourable temperature and moisture conditions (Ferraris, 1979; Campbell and White, 1982; Muchow et al., 1990).

Unfortunately, in Mediterranean environments early planting (April) may result in poor and non-homogeneous emergence, while later planting (mid-June) reduces biomass yields, due to a shorter available season associated to summer drought (Cosentino et al., 2004). In fact, a total $500-625 \mathrm{~mm}$ of $\mathrm{ET}_{\mathrm{C}}$ over a period of 5 to 6 months is considered essential for a successful production of kenaf fibre; that is to say, optimum yields should be achieved with a regular precipitation of about $125 \mathrm{~mm}$ of rainfall per month during the growing season (Muchow, 1992).

Given the issues still pending in the knowledge of kenaf behaviour, our research aimed at assessing the growing patterns of the two mentioned kenaf varieties at two plant densities in two seeding and harvest times, in a rainfed location of Northern Italy which may represent an upper boundary for kenaf diffusion $\left(45^{\circ} \mathrm{N}\right)$.

The work may be considered as a preliminary step to a growth modelling on a wider data-base, while at the same time offering an insight into crop behaviour under variable weather conditions and providing basic tools for an efficient, sustainable crop management.

\section{Material and methods}

\subsection{Experimental site}

Field trials were carried out in the years 2003, 2004 and 2005 at the Experimental Farm of 
Bologna University located in Cadriano, near Bologna, Italy (latitude $44^{\circ} 03^{\prime}$, longitude $11^{\circ} 02^{\prime}, 33$ $\mathrm{m}$ a.s.l.), in a flat area of the Po Valley. The farm soils are generally classified as Udic Ustochreps fine silty, mixed mesic (USDA classification); a physical-chemical analysis of the soils $(0-0.4 \mathrm{~m}$ depth) hosting the trials was made according to the Italian official methods (Anon., 1999).

The fields were ploughed in the autumn preceding each trial year. In springtime, $\mathrm{N}$-fertilizer was incorporated at seedbed preparation, at a rate of $100 \mathrm{~kg}$ of $\mathrm{N} \mathrm{ha}^{-1}$. No $\mathrm{P}$ and $\mathrm{K}$ was supplied, as their status was already adequate in the soil. The seed was mechanically sown $30-40 \mathrm{~mm}$ deep in amounts exceeding the target densities, according to the results of a germination test. Sowed plots were irrigated once $(20 \mathrm{~mm})$, to ease crop emergence. Weed control was performed by hand weeding soon after crop emergence and repeated later, if necessary. During growth, the trials were managed as rainfed crops, i.e. receiving only precipitation.

Daily meteorological data were recorded at the farm weather station, including minimum and maximum temperatures, precipitation and solar radiation. The heat sums from emergence to the end of the cycle were calculated assuming a basal temperature of $12{ }^{\circ} \mathrm{C}$, according to Carberry and Abrecht (1990), and expressed as growing degree days (GDD; ${ }^{\circ} \mathrm{C}$ ). Reference evapo-transpiration $\left(\mathrm{ET}_{0}\right)$ was estimated according to the equation by Hargreaves and Samani (1985):

$$
\mathrm{ET}_{0}=0.0023 \mathrm{RA} *(\mathrm{~T}+17.8) *\left(\mathrm{~T}_{\mathrm{x}}-\mathrm{T}_{\mathrm{n}}\right)^{0.50}
$$

where RA is extra-terrestrial radiation; $T, T_{x}$ and $\mathrm{T}_{\mathrm{n}}$ are average, maximum and minimum daily temperatures $\left({ }^{\circ} \mathrm{C}\right)$, respectively.

The formula offers a simplified method to calculate $\mathrm{ET}_{0}$ which is considered a possible alternative for environments not excessively windy or humid (Allen et al., 1998). Crop evapo-transpiration under standard conditions $\left(\mathrm{ET}_{\mathrm{C}}\right)$ was calculated by multiplying $\mathrm{ET}_{0}$ by crop coefficients $\left(\mathrm{K}_{\mathrm{C}}\right.$ 's), choosing $0.35,1.2$ and 0.5 respectively as initial, intermediate and final $\mathrm{K}_{\mathrm{C}}$ in analogy with cotton, another malvaceous for fibre production (Allen et al., 1998). According to phenological observations and in analogy with cotton, the lengths of the four crop development stages (intial, development, mid and late; Allen et al., 1998) were set at $20 \%$, $30 \%, 25 \%$ and $25 \%$ of crop cycle (emergence to $\mathrm{H} 1$ ) for $\mathrm{S} 1$; at $15 \%, 30 \%, 30 \%$ and $25 \%$ for $\mathrm{S} 2$.

A negative difference between output $\left(\mathrm{ET}_{\mathrm{C}}\right)$ and input (precipitation) represents the potential deficit of moisture.

\subsection{Experimental treatments}

Two seeding times (S1, early seeding; S2, late seeding), two harvest times (H1, early harvest; $\mathrm{H} 2$, late harvest), two genotypes (Everglades 41 and Tainung 2) and two plant densities (D1, 20 plants $\mathrm{m}^{-2} ; \mathrm{D} 2,40$ plants $\mathrm{m}^{-2}$ ) were cross tested in a completely randomized block design with three replications (Tab. 1). Each plot had a 42 $\mathrm{m}^{2}$ surface $(6 \times 7 \mathrm{~m})$. Rows were $0.5 \mathrm{~m}$ apart, while plant distance on the row was set at 0.1 $\mathrm{m}$ for $\mathrm{D} 1$ and at 0.05 for $\mathrm{D} 2$, to be achieved through thinning. The information concerning seeding, emergence and harvest dates in the three years is detailed in Table 1. The two genotypes were chosen among the top late maturing varieties for intermediate latitudes.

The fields hosting the trials had fine-textured soils with a strong silty component (400-500 g $\mathrm{kg}^{-1}$ ), which is typical of many lowland fields in the Po Valley. The $\mathrm{pH}$ was a moderate alkaline, in association with a good status of exchangeable calcium. The amount of organic matter (about 17 $\mathrm{g} \mathrm{kg}^{-1}$ ) was quite normal for the area, with a $\mathrm{C} / \mathrm{N}$ ratio (8.8 as average) showing a slight prevalence of the mineralization processes. Cation exchange capacity was at quite-good levels (average 17.5 cmol kg-1), thanks to a good clay content (about $250 \mathrm{~g} \mathrm{~kg}^{-1}$ ). Plant-available phosphorus and the three cationic nutrients $\mathrm{K}, \mathrm{Ca}$ and $\mathrm{Mg}$ were all at adequate to optimum status.

\subsection{Growth patterns and statistical analysis}

Several destructive harvests were performed on $0.75 \mathrm{~m}^{2}$ in each plot for the assessment of plant

Table 1. Seeding, emergence and final harvest dates in the three trial years.

\begin{tabular}{lcccc}
\hline & & 2003 & 2004 & 2005 \\
\hline Seeding dates & S1 & $19 / 5$ & $7 / 5$ & $28 / 4$ \\
& S2 & $19 / 6$ & $9 / 6$ & $30 / 5$ \\
Dates of & E1 & $24 / 5$ & $12 / 5$ & $9 / 5$ \\
emergence & E2 & $27 / 6$ & $15 / 6$ & $5 / 6$ \\
Final harvests & H1 & $5 / 11$ & $17 / 11$ & $16 / 12$ \\
& H2 & $4 / 12$ & $14 / 12$ & $21 / 1$ \\
\hline
\end{tabular}


growth during the cycle; they were a total of 7 (S1) and 6 (S2) in 2003; 10 for both seeding times in 2004 and in 2005. The last two harvests correspond to $\mathrm{H} 1$ and $\mathrm{H} 2$; they were performed during the autumn (autumn-winter in 2005) on larger areas $\left(5 \mathrm{~m}^{2}\right)$ for the evaluation also of yield and quality traits, whose data are beyond the scope of the present paper. For growth, at each harvest the following traits were assessed: actual plant density; stem height; base stem diameter; plant fresh biomass $\left(\mathrm{FB} ; \mathrm{g} \mathrm{m}^{-2}\right)$; dry matter content $\left(\mathrm{DM} ; \mathrm{g} \mathrm{kg}^{-1}\right)$; dry biomass $\left(\mathrm{DB} ; \mathrm{g} \mathrm{m}^{-2}\right.$ ) and, after partitioning into stems, leaves and petioles, dry stem biomass (DS; $\mathrm{g} \mathrm{m}^{-2}$ ) and leaf area index (LAI; $\mathrm{m}^{2} \mathrm{~m}^{-2}$; LI-3001, LI-COR, Lincoln, NE).

Radiation use efficiency (RUE) was determined as the slope of the linear regression of DB vs. intercepted photosynthetic active radiation $\left(\right.$ PAR $_{\mathrm{i}}$; Varlet-Grancher et al., 1989), cumulated over time. Given the particular importance of the stem as organ of commercial interest, RUE was also calculated for DS. PAR was obtained using the equation of Monsi and Saeki (1953) by means of the incoming PAR, the leaf area index and the extinction coefficient. Incoming PAR was determined by the total solar radiation measured at the farm weather station, assuming that $50 \%$ of the solar radiation is PAR (Monteith and Unsworth, 1990). A light extinction coefficient $(k)$ of 0.72 was adopted, according to Manzanares et al. (1993). To test slope differences among years of the regression lines used to determine RUE, the $t$ test was performed.

In order to analyse growth patterns, the traits were subjected to the procedure of curve fitting vs. heat sum or precipitation, using the SigmaPlot 8 (SPSS inc., Chicago, IL) software. For each trait, several models were tested, according to the shape of data scatter: linear, quadratic, exponential, sigmoid (logistic) and logarithmic. In choosing the most suitable model for each trait, particular attention was paid at the statistical significance (ANOVA) of both whole equation and single parameters, which means that significant equations with non-significant parameters were dismissed in favour of significant equations with significant parameters.

At last, Pearson's correlation (r) was tested among plant traits in order to evaluate the degree of inter-relation, and multiple linear re- gression (stepwise forward procedure) was used to evaluate the ability of some traits and environmental factors to predict kenaf growth, using the software SigmaStat 2.03 (SPSS, inc., Chicago, IL).

\section{Results}

\subsection{Environmental conditions}

The heat sum decreased from 2003 to 2005 (Tab. 2 ), in contrast to a parallel rise in the length of crop cycle: H1, always corresponding to the plateau in heat sum, in the mild 2005 autumn was placed at about the same time of the year as H2 in 2003 and 2004 (Tab. 1). In 2003, peaks

Table 2. Crop cycle, heat sum (GDD), precipitation, evapotranspiration $\left(\mathrm{ET}_{\mathrm{C}}\right)$ and moisture deficit in the three growing seasons. Initial, Development, Mid, Late, crop phases according to Allen et al., 1998. Precipitation, ET $_{\mathrm{C}}$ and Deficit values refer to the average of the two seeding times, up to the plateau of heat sums (H1). E1 and E2 refer to emergence in the two seeding times (S1 and S2, respectively).

\begin{tabular}{|c|c|c|c|}
\hline & 2003 & 2004 & 2005 \\
\hline \multicolumn{4}{|c|}{ Crop cycle (days) } \\
\hline $\mathrm{E} 1-\mathrm{H} 1$ & 166 & 190 & 222 \\
\hline $\mathrm{E} 1-\mathrm{H} 2$ & 195 & 217 & 258 \\
\hline $\mathrm{E} 2-\mathrm{H} 1$ & 132 & 156 & 195 \\
\hline $\mathrm{E} 2-\mathrm{H} 2$ & 161 & 183 & 231 \\
\hline \multicolumn{4}{|l|}{$\operatorname{GDD}\left({ }^{\circ} \mathrm{C}\right)$} \\
\hline $\mathrm{E} 1-\mathrm{H} 1$ & 1733 & 1542 & 1433 \\
\hline $\mathrm{E} 2-\mathrm{H} 1$ & 1286 & 1325 & 1253 \\
\hline Mean & 1509 & 1434 & 1343 \\
\hline \multicolumn{4}{|c|}{ Precipitation (mm) } \\
\hline Initial & 27 & 22 & 50 \\
\hline Development & 18 & 89 & 34 \\
\hline Mid & 24 & 7 & 118 \\
\hline Late & 31 & 71 & 281 \\
\hline Total & 101 & 189 & 484 \\
\hline \multicolumn{4}{|l|}{$\mathrm{ET}_{\mathrm{C}}(\mathrm{mm})$} \\
\hline Initial & 46 & 45 & 47 \\
\hline Development & 178 & 186 & 203 \\
\hline Mid & 205 & 228 & 212 \\
\hline Late & 84 & 89 & 80 \\
\hline Total & 513 & 548 & 542 \\
\hline \multicolumn{4}{|c|}{ Deficit (Prec. - ETC) } \\
\hline Initial & -19 & -23 & 4 \\
\hline Development & -159 & -97 & -169 \\
\hline Mid & -181 & -221 & -93 \\
\hline Late & -53 & -18 & 201 \\
\hline Total & -412 & -360 & $-259 *$ \\
\hline
\end{tabular}

* The surplus in the late phase $(201 \mathrm{~mm})$ was not considered in this sum. 


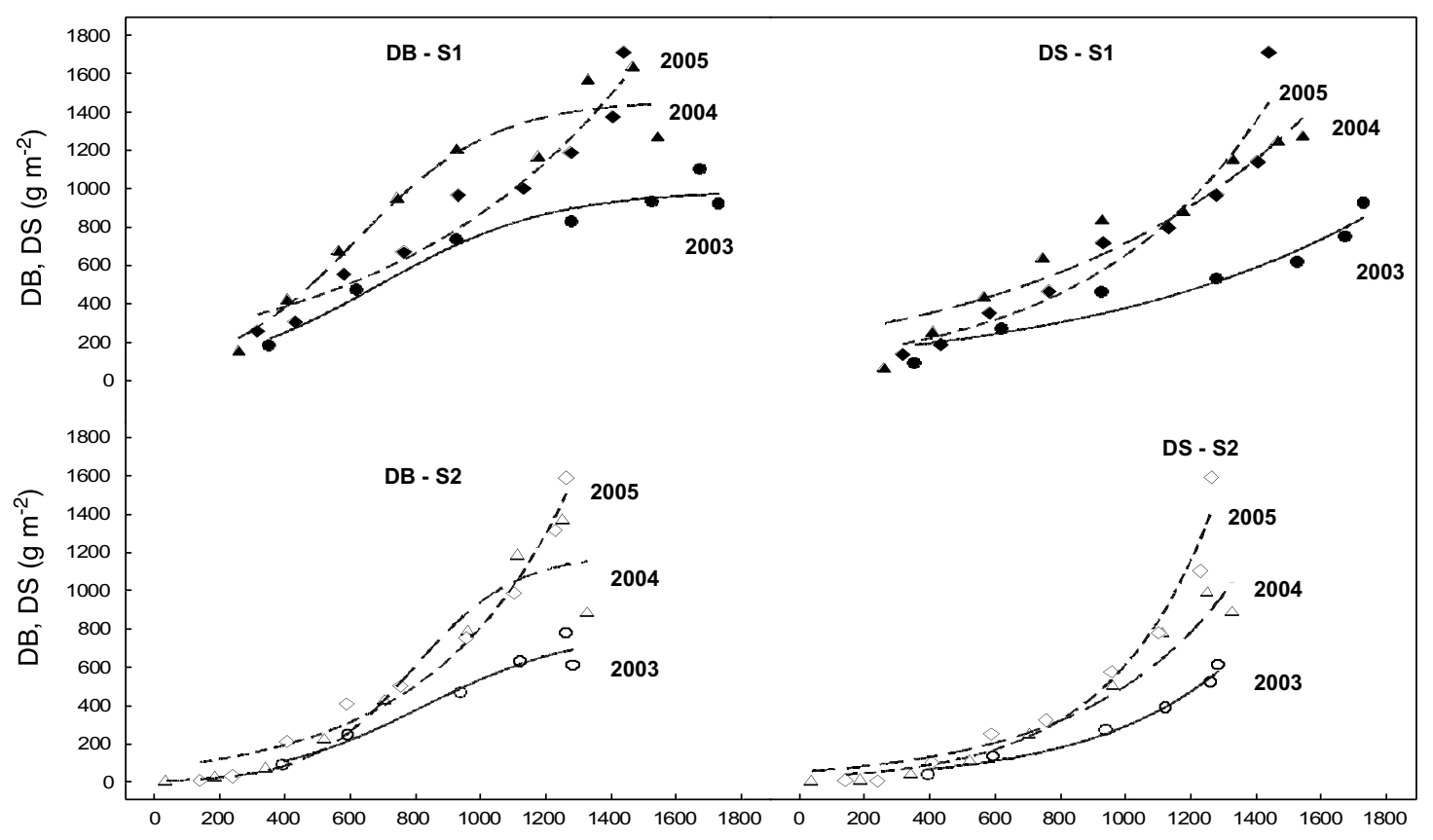

Figure 1. Dry biomass (DB) and dry stem (DS) of early (S1) and late (S2) seeding vs. heat sum (GDD) in the three years. Circles, triangles and diamonds, year 2003, 2004 and 2005, respectively. Filled and empty symbols, S1 and S2, respectively. Equation types and parameters are reported in Table 3. For each year and seeding time, points are the average of the two genotypes and plant densities.

around $35{ }^{\circ} \mathrm{C}$ were repeatedly reached during the summertime.

The potential need of water $\left(\mathrm{ET}_{\mathrm{C}}\right)$ was 513 , 548 and $542 \mathrm{~mm}$ in 2003, 2004 and 2005, respectively (S1-S2 average). Compared to precipitation, it originated a potential deficit decreasing from 2003 to 2005: 412, 360 and 259 $\mathrm{mm}$, respectively (S1-S2 average). Displacing crop cycle from S1 to S2 did not significantly affect the deficit (data not shown), since both precipitation and $\mathrm{ET}_{\mathrm{C}}$ decreased in a similar way.

\subsection{Whole-plant biomass}

In 2003 and 2004, DB rose up to the sampling time preceding $\mathrm{H} 1$, then lost an average 20$30 \%$. This was in contrast to an equivalent gain in the same time interval for the more favourable year 2005 (Fig. 1).

$\mathrm{H} 2$ was dismissed from the process of curve fitting, since after $\mathrm{H} 1$ average temperatures consistently passed below $12{ }^{\circ} \mathrm{C}$ (minimum threshold for potential growth). The two varieties and the two densities followed statistically indifferent patterns and were averaged. Therefore, the average variety and density data were plotted up to H1, which leaves a total of six year $\mathrm{x}$ seeding time combinations to be interpreted (Fig. 1). In the first two years, the sigmoid model provided the best fitting for both seeding times. Its general shape is given by the equation:

$$
\mathrm{y}=a /\left(1+e^{-(x-x 0) / b}\right)
$$

where: $\mathrm{y}=$ dry biomass $\left(\mathrm{g} \mathrm{m}^{-2}\right) ; a=$ asymptotic yield $\left(\mathrm{g} \mathrm{m}^{-2}\right) ; x=$ heat sum (GDD); $x_{0}=$ heat sum at the point of inflection (GDD); $b=$ 1/growth rate (GDD ${ }^{-1} \mathrm{~m}^{2}$ ).

The equation explained over $90 \%$ of the total variation (adjusted $\mathrm{R}^{2}$ ), according to year and seeding time (Tab. 3), with a good significance of whole equation and single parameters. In both years $\mathrm{S} 1$ showed a higher growth potential ( $a$ parameter) than S2; likewise, 2004 had a higher potential than 2003. Differences in growth rates were in agreement with those in the plateau yields: S2 consistently grew faster than S1 (lower $b$ values), as well as the second vs. the first year. At last, the point of inflection was always placed at a later time in S2 than in S1. 
Table 3. Parameters and their values in fitted curves for dry biomass (DB) and dry stem (DS) vs. heat sum (GDD); for DS vs. precipitation (Prec.); for DB and DS vs. intercepted photosynthetic active radiation ( PAR $_{\mathrm{i}}$ ). " $y_{0}$ ” means: $\mathrm{y}$-axis intercept (logarithmic model; $\mathrm{g} \mathrm{m}^{-2}$ ). " $a$ " means: asymptotic yield (sigmoid model; $\mathrm{g} \mathrm{m}^{-2}$ ); y-axis intercept (exponential mod$\mathrm{el} ; \mathrm{g} \mathrm{m}^{-2}$ ); growth-rate constant (logarithmic model; $\mathrm{g} \mathrm{m}^{-2} \mathrm{GDD}^{-1}$ ); RUE (linear model; $\mathrm{g} \mathrm{m}^{-2} \mathrm{MJ}^{-1}$ ). " $b$ " means: $1 /$ growth rate (sigmoid model; GDD g-1 $\mathrm{m}^{2}$ ); growth-rate constant (exponential model; $\mathrm{g} \mathrm{m}^{-2} \mathrm{GDD}^{-1}$ ). " $x_{0}$ " represents the point of inflection (sigmoid model; GDD).,$+{ }^{*}$ and $* *$ mean significant at $P \leq 0.10, P \leq 0.05$ and $P \leq 0.01$, respectively.

\begin{tabular}{|c|c|c|c|c|c|c|}
\hline Year and sowing & Model & Adj. $\mathrm{R}^{2}$ & $\mathrm{y}_{0}$ & a & $\mathrm{b}$ & $\mathbf{x}_{0}$ \\
\hline \multicolumn{7}{|l|}{ DB vs. GDD } \\
\hline $2003-\mathrm{S} 1$ & sigmoid & $0.93 * *$ & & $993,9 * *$ & $264.0 *$ & $682.4 * *$ \\
\hline $2003-S 2$ & sigmoid & $0.91^{*}$ & & $794.0 *$ & $235.6+$ & $822.3 *$ \\
\hline $2004-S 1$ & sigmoid & $0.91 * *$ & & $1462.2 * *$ & $210.3 *$ & $615.8 * *$ \\
\hline $2004-\mathrm{S} 2$ & sigmoid & $0.90 * *$ & & $1192.7 * *$ & $155.4+$ & $791.8 * *$ \\
\hline $2005-\mathrm{S} 1$ & exponential & $0.94 * *$ & & $226.9 * *$ & $0.0013 * *$ & \\
\hline $2005-S 2$ & exponential & $0.98 * *$ & & $76.5 * *$ & $0.0024 * *$ & \\
\hline \multicolumn{7}{|l|}{ DS vs. GDD } \\
\hline $2003-\mathrm{S} 1$ & exponential & $0.92 * *$ & & $122.8 *$ & $0.0011 * *$ & \\
\hline $2003-\mathrm{S} 2$ & exponential & $0.98 * *$ & & $26.7 *$ & $0.0024 * *$ & \\
\hline $2004-S 1$ & exponential & $0.90 * *$ & & $216.3 * *$ & $0.0012 * *$ & \\
\hline $2004-\mathrm{S} 2$ & exponential & $0.93 * *$ & & $54.8+$ & $0.0022 * *$ & \\
\hline $2005-\mathrm{S} 1$ & exponential & $0.91 * *$ & & $105.2 *$ & $0.0018 * *$ & \\
\hline $2005-\mathrm{S} 2$ & exponential & $0.96 * *$ & & $25.8+$ & $0.0032 * *$ & \\
\hline \multicolumn{7}{|l|}{ DS vs. Precipitation } \\
\hline Cumulated years - S1 & logarithmic & $0.86 * *$ & $-2055.1 * *$ & $560.8 * *$ & & \\
\hline \multicolumn{7}{|l|}{ DB vs. PARi } \\
\hline $\mathrm{S} 1$ & linear & $0.83 * *$ & & $1.35 * *$ & & \\
\hline $\mathrm{S} 1$ & linear & $0.82 * *$ & & $1.69 * *$ & & \\
\hline \multicolumn{7}{|l|}{ DS vs. PARi } \\
\hline $\mathrm{S} 1$ & linear & $0.92 * *$ & & $1.01 * *$ & & \\
\hline $\mathrm{S} 2$ & linear & $0.94 * *$ & & $1.23 * *$ & & \\
\hline
\end{tabular}

In the third year (2005), the sigmoid equation was still able to explain a very high share of the total variation, but the single parameters were seldom significant. Therefore, it was dismissed in favour of an exponential growth model which supplied the best fit for the dataset (Fig. 1), although this model does not express a plateau yield as the sigmoid one. Its shape is given by the equation:

$$
\mathrm{y}=a^{*} e^{(b x)}
$$

where: $\mathrm{y}=$ dry biomass $\left(\mathrm{g} \mathrm{m}^{-2}\right)$; $\mathrm{a}=\mathrm{y}$-axis intercept $\left(\mathrm{g} \mathrm{m}^{-2}\right) ; \mathrm{b}=$ growth-rate constant $\left(\mathrm{g} \mathrm{m}^{-2}\right.$ $\left.\mathrm{GDD}^{-1}\right) ; \mathrm{x}=$ heat sum (GDD).

The equation explained about $95 \%$ of total variation, with a high significance for both whole equation and single parameters (Tab. 3). S2 showed a lower intercept but an almost double growth rate, which means a faster growth in a shorter season. As a result, growth differences between $\mathrm{S} 1$ and $\mathrm{S} 2$ at the end of the cycle were minimal in 2005, compared to the previous two years.

\section{Stem biomass}

The two genotypes and plant densities were averaged and $\mathrm{H} 2$ was dismissed from DS curve fitting (Fig. 1 and Tab. 3), for the same reasons as for DB. The exponential growth model always offered a good and consistent fit, with amounts of explained variation ranging from 90 to $98 \%$ and with a good statistical significance of the whole equation and, with minor exceptions, of the single parameters.

The parameter values in the six exponential equations (Tab. 3) always showed an almost double rate constant $(b)$ in $\mathrm{S} 2$ than in $\mathrm{S} 1$, implying a faster build-up of stem biomass in the conditions of a shorter growing season.

Plotting stem biomass vs. precipitation instead of heat sum may offer good hints in conditions of limited water resources, like those of these trials. The three-year dataset of only S1 was used, which had originated more consistent trends. A logarithmic model provided the best fit for the data (Fig. 2 and Tab. 3). Its equation was:

$$
\mathrm{y}=y_{0}+a^{*} \ln (\mathrm{x})
$$




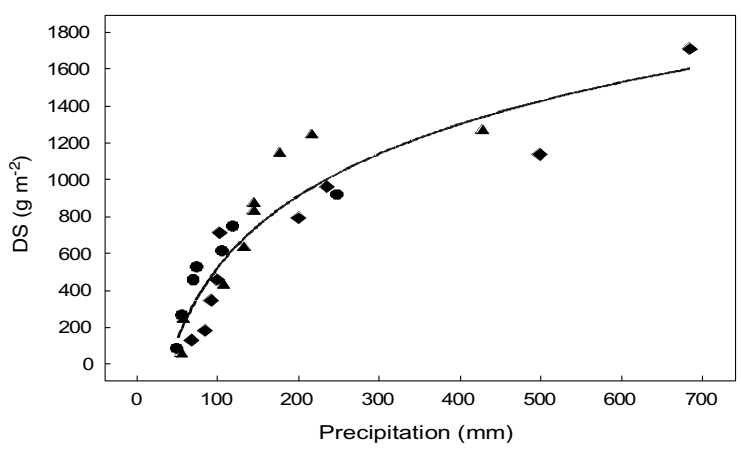

Figure 2. Dry stem curves vs. precipitation in the early seeding (S1) of the three trial years. Circles, triangles and diamonds, year 2003, 2004 and 2005, respectively. Equation type and parameters are reported in Table 3. For each year, points are the average of the two genotypes and plant densities.

where $y_{0}=\mathrm{y}$-axis intercept $\left(\mathrm{g} \mathrm{m}^{-2}\right) ; a=$ growthrate constant $\left(\mathrm{g} \mathrm{m}^{-2} \mathrm{GDD}^{-1}\right)$.

Compared to the single year equations (unreported; adj. $\mathrm{R}^{2}$ between 0.85 and 0.90 ), the common fit maintained a good predictability $\left(\operatorname{adj} . \mathrm{R}^{2}=0.86\right)$ and statistical significance $(P \leq$ $0.01)$, showing a declining growth as the amount of precipitation rose.

\subsection{Biomass growth in relation to plant traits and environmental factors}

Applying an allometric approach to the whole three-year dataset, i.e. including the two genotypes, the two densities and the two seeding and harvest times $(n=660)$, originated the cross correlations reported in Table 4. All the traits resulted highly inter-related, except one case (DM with FB). DB and DS exhibited high associations with plant height and base stem diameter ( $\mathrm{r}$ ranging from 0.65 to 0.90 ). $\mathrm{FB}$, the simplest of destructive parameters since it does not require oven drying, equally proved to be well as- sociated to DB and DS ( $\mathrm{r}=0.85$ and 0.72 , respectively).

In a multiple linear regression of Height, Diameter and FB on DB and DS (stepwise selection, forward procedure), all the three potential regressors were chosen by the procedure. The amount of explained variation with respect to the best simple regression (that with Height) varied according to the trait: for $\mathrm{DB}$, adj. $\mathrm{R}^{2}$ rose from 0.740 to 0.878 ; for DS, from 0.804 to 0.836 . In both cases, Diameter was the last parameter to be picked by the procedure, i.e. that delivering the weakest contribution.

More to that, multiple linear regression allowed to assess kenaf growth through the two environmental factors which had singularly proved to be most influential on growth: heat and moisture. Their association over the whole three-year dataset up to $\mathrm{H} 1$, in the average of the three replicates $(n=196)$, led to the following regressions:

$$
\begin{gathered}
\text { DB }=-41.3+0.689 * \text { GDD }+1.063 * \\
\text { Precipitation; adj. } \mathrm{R}^{2}=0.76^{* *} \\
\text { DS }=-110.6+0.480 * \mathrm{GDD}+1.563 * \\
\text { Precipitation; adj. } \mathrm{R}^{2}=0.86^{* *}
\end{gathered}
$$

with DB, DS, GDD and Precipitation expressed in the previously adopted units.

\subsection{Light interception}

LAI appeared to be poorly related to whole plant or stem growth (Fig. 3): in S1, LAI reached 7.1, 5.1 and $3.8 \mathrm{~m}^{2} \mathrm{~m}^{-2}$ in 2004, 2003 and 2005, respectively. This was in contrast with the buildup of plant biomass: highest in 2005, intermediate in 2004, lowest in 2003. In S2, both rise and fall of leaf canopy were steeper than in S1; differences among the years were not so consistent, although 2004 remained atop the other two years.

\begin{tabular}{|c|c|c|c|c|c|c|}
\hline Plant trait & Height & Diameter & FB & $\mathrm{DM}$ & DB & DS \\
\hline Diameter & $0.75 * *$ & & & & & \\
\hline FB & $0.68 * *$ & $0.66 * *$ & & & & \\
\hline DM & $0.62 * *$ & $0.35 * *$ & $0.03 \mathrm{~ns}$ & & & \\
\hline DB & $0.86 * *$ & $0.70 * *$ & $0.85 * *$ & $0.48 * *$ & & \\
\hline DS & $0.90 * *$ & $0.65 * *$ & $0.72 * *$ & $0.62 * *$ & $0.96 * *$ & \\
\hline LAI & $0.56 * *$ & $0.63 * *$ & $0.62 * *$ & $0.37 * *$ & $0.63 * *$ & $0.56 * *$ \\
\hline
\end{tabular}

Table 4. Correlations (r) between plant traits during the three growing seasons. $\mathrm{FB}=$ fresh biomass; $\mathrm{DM}=$ dry matter content; $\mathrm{DB}=$ dry biomass; $\mathrm{DS}=$ dry stem. ns, ${ }^{*}$ and $* *$ means insignificant, significant at $P \leq 0.05$ and at $P \leq 0.01$, respectively $(\mathrm{n}=660)$. 


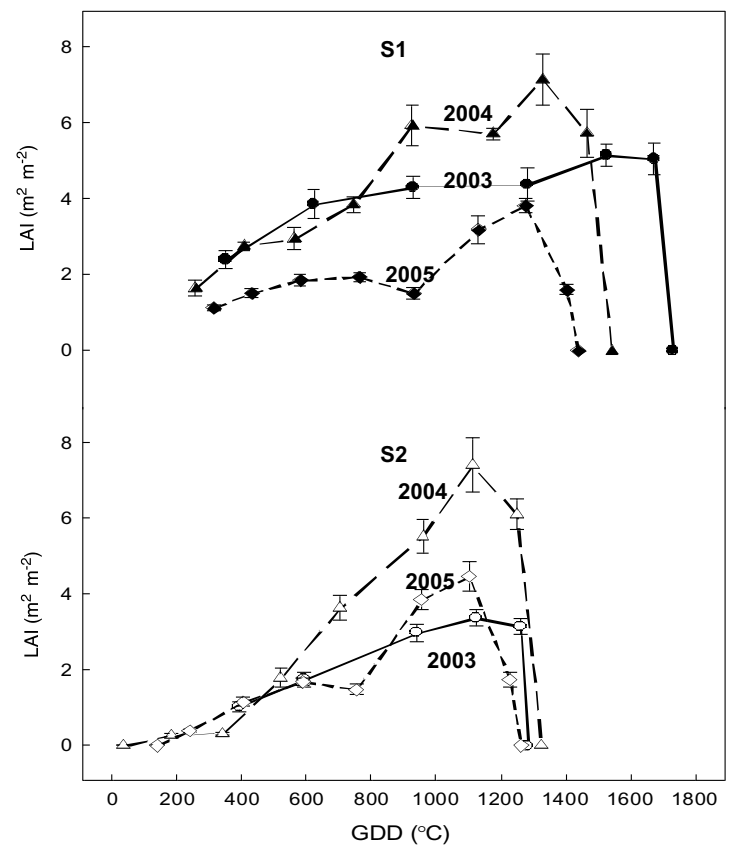

Figure 3. LAI course vs. heat sum (GDD) in early (S1) and late (S2) seeding in the three trial years. Circles, triangles and diamonds, year 2003, 2004 and 2005, respectively. Filled and empty symbols, S1 and S2, respectively. For each year and seeding time, points are the average of the two genotypes and plant densities. Vertical bars, \pm SE $(n=12)$.

In plotting DB and DS against intercepted radiation (Fig. 4 and Tab. 3), the three years were not statistically different and were grouped, whereas the two seeding times originated separate trends (significant $t$ test). The amount of variation explained by a linear model $\left(\operatorname{adj} . \mathrm{R}^{2}\right)$ passed $80 \%$ for DB; $90 \%$ for DS (Tab. 3). For both DB and DS, RUE $(a)$ increased about $25 \%$ when passing from S1 to S2, whereas it decreased by an equivalent amount, when passing from DB to DS in both seeding times.

\section{Discussion}

The three years were progressively cooler, so that the parallel lengthening of crop cycle could hardly compensate for the decreasing temperatures (Tab. 2). However, the high heat sum of the year 2003 depends on summer temperatures possibly exceeding kenaf optimum, although to our knowledge no optimum or maximum temperatures has been set for kenaf growth in mid phases, in contrast to the early ones (Carberry and Abrecht, 1990, Angelini et al., 1998). This may explain the lower growth at the end of the season observed in 2003 with respect to 2004 and, especially, to 2005 (Fig. 1).

Since kenaf is a short day species (Dempsey, 1975), crop growth and development depend on heat sum as well as on photoperiodic needs. In our research we relied on heat sums only, which may be justified during the plant's vegetative phase (Carberry et al., 1992). In our research flowering only took place in the year of longest crop cycle, but also of highest growth level (2005). This leads us to believe that even a partial shift from vegetative to reproductive growth does not represent a serious constraint for the build-up of biomass.

In a parallel research carried out with the same protocol, Danalatos and Archontoulis (2005) argued that the growth differences between S1 and S2 are only attributable to the longer vegetation of $\mathrm{S} 1$, with yield reductions up to $20 \%$ for a seeding delay of one month with

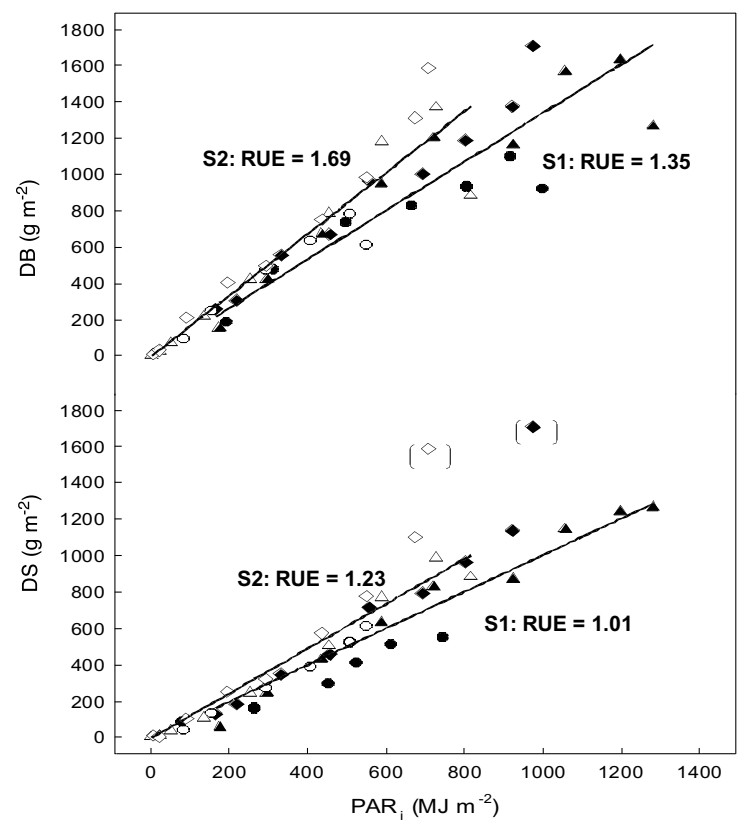

Figure 4. Cumulated dry biomass (DB) and dry stem (DS) of early (S1) and late (S2) seeding vs. cumulated intercepted photosynthetic active radiation $\left(\mathrm{PAR}_{\mathrm{i}}\right)$. Circles, triangles and diamonds, year 2003, 2004 and 2005, respectively. Filled and empty symbols, S1 and S2, respectively. Equation types and parameters are reported in Table 3. For each seeding time, points are the average of the two genotypes and plant densities. Within brackets, outliers. 
respect to an early time. These findings are in agreement with our results: final growth differences between S1 and S2 tended to fade in 2005 (Fig. 1), when the relative cycle length difference was small, compared to the other two years (Tab. 2). The adoption of genotypes able to germinate at temperatures of $8-10{ }^{\circ} \mathrm{C}$ (Carberry and Abrecht, 1990; Angelini et al., 1998) and the breeding of new ones retaining this trait may, therefore, be seen as a key tool to lengthen crop cycle and improve yields.

Danalatos and Archontoulis (2005) also found negligible genotype and plant density effects throughout the cycle, still in agreement with our results. Therefore, the choice of either variety in lowland locations at latitudes of 40$45^{\circ}$ may be seen as an equivalent option, whereas the thinner density entails valuable savings in the cost of seed per hectare, at no prejudice for potential yield.

Kenaf can exert a high stomatal control under conditions of drought stress (Muchow, 1992). This behaviour allows recovery after stress, although water deficit severely affects biomass yield (Muchow, 1992), and the crop has been shown to significantly respond to irrigation (Manzanares et al., 1993; Mambelli and Grandi, 1995). Our rain-fed experience cannot compare with irrigation studies. However, stem growth vs. heat was weaker in 2003 than in 2004 and 2005 (Fig. 1), whereas the trend vs. precipitation was consistent among the three years (Fig. 2). It is perceived, therefore, as in 2003 growth was more constrained by a lack of moisture, which impaired the plant's ability to exploit the available heat sum with respect to the other two years. The same 2003 year was the one showing the highest moisture deficit: $80 \%$ of potential consumption $\left(\mathrm{ET}_{\mathrm{C}}\right)$ with respect to $66 \%$ of 2004 and $48 \%$ of 2005 (Tab. 2).

To our knowledge, kenaf growth has not yet been described by means of mathematical functions at intermediate latitudes, whereas it has extensively been modelled at low latitudes (12$20{ }^{\circ} \mathrm{S}$; Carberry et al., 1992). Therefore, it is not possible to compare our fittings with others. Amid our data, it can only be remarked as equation parameters in both sigmoid (DB in 2003 and 2004) and exponential growth curves (DB in 2005; DS) outline a picture of increasing growth speed between S1 and S2, as well as from 2003 to 2005 . The former is consistent with the higher temperatures at the beginning of growth which are proper of a later seeding; the latter is incidental but in good agreement with the environmental conditions registered during the trials. The high dependence of DB and especially of DS on associated heat and rain (adj. $\mathrm{R}^{2} 0.76$ and 0.86 , respectively) supports this point and attributes a non-negligible power of prediction to the respective regressions, in the light of the varied environmental conditions met in the three years.

Also, the correlations among plant traits (Tab. 4) offer the opportunity of estimating growth through the measure of non-destructive parameters, thus avoiding the burden of destructive samplings and associated operations. In the same environment, Mambelli and Grandi (1995) found equally good correlations in the final phases of crop cycle, which encourages the adoption of allometric measurements as a tool of potential support for biomass assessments in commercial fields.

The correlations, although significant, do not seem reliable enough for the prediction of LAI, given its rapid fall after the mid-September peak. This trend had already been observed at intermediate latitudes, in both rainfed and irrigated conditions (Danalatos and Archontoulis, 2005). The growth of leaf canopy involves the assessment of the rate of plant node production, and of leaf area expansion and senescence per node, which have been described by empirical functions at low latitudes (Carberry and $\mathrm{Mu}$ chow, 1992). Our data are not articulate enough as to allow a similar interpretation of LAI course, whereas the trait is functional to the assessment of RUE, a basic parameter for growth modelling. In our research, RUE showed a base value (DB in S1) of $1.35 \mathrm{~g} \mathrm{MJ}^{-1}$, much lower than obtained in another experience in near optimal conditions in the Mediterranean area (2.45 $\mathrm{g} \mathrm{MJ}^{-1}$; Manzanares et al., 1993). A lower value observed in a semi-arid tropical environment (1.20 $\mathrm{g} \mathrm{MJ}^{-1}$; Muchow, 1992) refers to total radiation, not to PAR, which is assumed to be $50 \%$ of it. Since RUE may significantly be affected by water availability (Arkebauer et al., 1994; Muchow et al., 1993), the gap between our data and those of other experiences may be explained by the constraint imposed by lack of moisture. Conversely, it may be excluded that RUE was constrained by low nitrogen avail- 
ability, since in parallel trials in the same experimental site and in the same three years the response to nitrogen fertilization $\left(0-150 \mathrm{~kg} \mathrm{ha}^{-1}\right.$ range) was always weak.

\section{Conclusion}

In our experiment, curve fitting always offered a reliable description of kenaf growth pattern. The crop generally grew according to a sigmoid and to an exponential model for DB and DS, respectively. Among the four investigated factors, seeding and harvest time, genotype and plant density, only seeding time originated consistent differences in equation parameters among years, showing a higher asymptotic yield and, conversely, a lower growth rate and RUE in S1 with respect to S2. As for the remaining factors, a delayed harvest did not extend the potential growing season, while the choice of either variety and plant density was not influential, the latter potentially involving some savings in the cost of seed. Therefore, the possibility of extending the growing season may only be sought in the anticipation of seeding time, if possible in association with genotypes bred for cold resistance. The different weather conditions met in the three years highlighted the importance of moisture as a condition to exploit the available heat sum. The good correlations and multi-linear regressions between heat and rain, on one side, and plant/stem growth, on the other, represent valuable tools of potential support for yield forecasts.

\section{Acknowledgements}

This work has been funded by the EU project BIOKENAF "Biomass Production Chain and Growth Simulation model for Kenaf Contract No: QLK5 CT2002 01729".

\section{References}

Alexopoulou E., Christou M., Mardikis M., Chatziathanassiou A. 2000. Growth and yields of kenaf varieties in central Greece. Ind. Crop Prod., 11:163-172.

Allen R.G., Pereira L.S., Raes D., Smith M.1998. Crop evapotranspiration - Guidelines for computing crop water requirements - FAO Irrigation and drainage paper 56.

Angelini L.G., Macchia M., Ceccarini L., Bonari E. 1998. Screening of kenaf (Hibiscus cannabinus L.) geno- types for low temperatures requirements during germination and evaluation of feasibility of seed production in Italy. Field Crop Res., 59:73-79.

Anonymous 1999. D.M. 13/09/99. Ministero per le Politiche Agricole. Metodi ufficiali di analisi chimica del suolo. Gazzetta Ufficiale n. 248 del 21/10/99 (in Italian).

Arkebauer T.J., Weiss A., Sinclair T.R., Blum A. 1992. In defence of radiation use efficiency: a response to Demetriades-Shah et al., 1992. Agric. For. Meteorol., 68:222-227.

Campbell T., White G. 1982. Production density and planting date effects on kenaf performance. Agron. J., 74:74-77.

Carberry P.S., Abrecht D.G. 1990. Germination and elongation of the hypocotyl and radicle of kenaf (Hibiscus cannabinus L.) in response to temperature. Field Crops Res., 24:227-240.

Carberry P.S., Muchow R.C. 1992. A simulation model of kenaf for assisting fibre industry planning in Northern Australia. II. Leaf area development. Austr. J. Agric. Res., 43:1515-1526.

Carberry P.S., Muchow R.C. Williams R., Sturtz J.D., Mc Cown R.L. 1992. A simulation model of kenaf for assisting fibre industry planning in Northern Australia. I. General introduction and phenological model. Austr. J. Agric. Res., 43:1501-1513.

Cosentino S.L., D’Agosta G.M., Copani V., Testa G. 2004. Yield and development of kenaf (Hibiscus cannabinus L.) crop in relation to genotype, sowing time and plant population in Mediterranean environment. Proceedings of the $2^{\text {nd }}$ World Biomass Conference, 10-14 May, Rome, Italy, 381-384.

Danalatos N.G., Archontoulis S.V. 2005. Sowing time and plant density effects on growth and biomass productivity of two kenaf varieties in central Greece. International Conference on Industrial Crops and Rural Development, September 17-21, Murcia, Spain, http://www.aaic.org/05progrm.htm.

Dempsey J.M. 1975. Fibre crops. The University Press of Florida, Gainesville, Florida.

Di Virgilio N., Amaducci M.T., Vecchi A., Venturi G. 2004. Effects of environmental and agronomic factors on kenaf (Hibiscus cannabinus L.) in Po Valley. Proceedings of the $2^{\text {nd }}$ World Biomass Conference, 10-14 May, Rome, Italy, 271-273.

Ferraris R. 1979. Effect of time of sowing and age at harvest on kenaf (Hibiscus cannabinus L.) in the wet tropics. J. Aust. Inst. Agric. Sci., 45:132-136.

Fuller M.J. (ed.) 1994. A summary of kenaf production and product development research 1989-1993. Miss. Agric. And Forestry Exp. Sta., Mississipi State, MS, Bullettin 1011, 23-33.

Hargreaves G.H., Samani Z.A. 1985. Reference crop evapotranspiration from temperature. Applied Engineering in Agriculture, ASAE, 1:96-99.

Hays S.M. 1989. Kenaf tops equal high-quality hay. USDAARS Agric. Res., 37:18. 
Higgins J.J., White G.A. 1970. Effects of plant population and harvest date on stem yield and growth components of kenaf in Maryland. Agron. J., 62:667-668.

Kugler D.E. 1990. Non-wood Fiber Crops: Commercialization of Kenaf for newsprint. In: Janick J., Simon J.E. (eds.): Advances in new crops, 289-292. Timber Press, Portland, OR, USA.

Liu A. (ed.) 2003. International development of kenaf and allied fibers. CCG International inc. Minneapolis, MN, USA.

Mambelli S., Grandi S. 1995. Yield and quality of kenaf (Hibiscus cannabinus L.) stem as affected by harvest date and irrigation. Ind. Crop Prod., 4:97-104.

Manzanares M., Tenorio J.L., Manzanares P., Ayebre L. 1993. Yield and development of kenaf (Hibiscus cannabinus L.) crop in relation to water supply and intercepted radiation. Biomass Bioenerg., 5:337-345.

Manzanares M., Tenorio J., Ayerbe L. 1997. Sowing time, cultivar, plant population and application of $\mathrm{N}$ fertilization on kenaf in Spain's central plateau, Biomass Bioenerg., 12:263-271.

Monsi M., Saeki T. 1953. Über den Lichtfaktor in den Pflanzengesellschaften und seine Bedeutung für die Stoffproduktion. Jpn. J. Bot., 14:22-52.

Monteith J.L., Unsworth M.H. 1990. Principles of Environmental Physics. Edward Arnold, Hodder Headline PLC, London, GB.

Muchow R.C. 1979. Effects of plant population and season on kenaf (Hibiscus cannabinus L.) grown under irrigation in tropical Australia. I - Influence on the components of yield. Field Crop Res., 2:55-66.

Muchow R.C. 1992. Effect of water and nitrogen supply on radiation interception and biomass accumulation of kenaf in a semi-arid tropical environment. Field Crop Res., 28:281-293.

Muchow R.C., Robertson M.J., Pengelly B.C. 1993. Radiation use efficiency of soybean, mungbean and cowpea under different environmental conditions. Field Crop. Res., 32:1-16.
Muchow R.C., Sturtz J.D., Spillman M.F., Routley G.E., Kaplin S., Martin C., Bateman R. 1990. Agronomic studies on the productivity of kenaf (Hibiscus cannabinus L. cv. Guatemala 4) under rainfed conditions in the Northern Territory. Aust. J. Exp. Agric., 30:395-403.

Petrini C., Bazzocchi R., Montalti P. 1994. Yield potential and adaptation of kenaf (Hibiscus cannabinus L.) in north-central Italy. Ind. Crop Prod., 3:11-15.

Shimizu K., Omura M., Cao W., Ishikawa N. 2004. Comparison of biomass production and photosymthetic characteristics in some varieties of kenaf. Jpn. J. Trop. Agr., 48:35-39.

Taylor C.S. 1992. Kenaf: annual fiber crop products generate a growing response from industry: new crops, new uses, new markets. In: 1992 Yearbook of Agriculture. Office of Publishing and Visual Communication, USDA, Washington, DC, III, 92-98.

USDA 1993. Kenaf. In: Harsch (ed.): New industrial uses, new market for U.S. crops. USDA-CSRS, office of Agr. Materials, Washington, DC, 46-49.

Varlet-Grancher C., Gosse G., Chartier M., Sinoquet H., Bonhomme R., Allirand J.M. 1989. Mise au point: rayonnement solaire absorbé ou intercepté par un couvert végétal. Agronomie, 9:419-439.

Webber C.L., Bledsoe R.E. 1993. Kenaf: Production, harvesting, processing, and products. In: Janick J., Simon J.E. (eds.): New Crops, 416-421. Wiley Publ., New York.

Webber Ch.L., Bhardwaj H.L., Bledsoe V.K. 2002. Kenaf production: Fiber, feed and seed. In: Janick J., Whipkey A. (eds): Trends in New Crops and New Uses, 327-339. ASHS Press, Alexandria, VA, USA.

White G.A., Adamson W.C., Higgins J.J. 1971. Effect of population levels on growth factors in kenaf varieties. Agron. J., 63:233-235.

Wood I.M., Muchow R.C., Ratcliff D. 1983. Effect of sowing date on the growth and yield of kenaf (Hibiscus cannabinus) grown under irrigation in tropical Australia. 11, Stem production. Field Crop Res., 7:91-102. 